\title{
A Study of Bending Property for Glass Fiber Reinforced Thermoplastic Composite Sheets
}

\author{
Mustafa Faisal Zaidan ${ }^{1} *$, Khudhayer J. Jadee ${ }^{1}$, Salwa A. Abed ${ }^{2}$ \\ ${ }^{1}$ Technical Engineering College-Baghdad, Middle Technical University, Baghdad, Iraq. \\ ${ }^{2}$ Technical Institute of Baquba, Middle Technical University, Baghdad, Iraq.
}

\begin{abstract}
In this research a study of the influence of percentage for chopped fiber glass reinforcement thermoplastic sheet on the flexural strength. Hot compression method used to fabricate thermoplastic (polypropylene and polyamide) reinforced by fiber glass at different percentage $(10,20,30,40) \mathrm{wt}$. $\%$, the flexural strength test done by using three-point bending test. The results shown that for bending test the sample glass fiber reinforcement polyamide (GFRPA) and sample glass fiber reinforcement polypropylene (GFRPP), which reinforced with $40 \%$ fiber glass achieved the high magnitude of flexural strength (106.1 and 70.8) MPa respectively. While the sample polyamide (PA) and polypropylene (PP) without reinforcement show the lowest magnitude of flexural strength (59.5 and 38.4) MPa respectively.
\end{abstract}

Keywords: Flexural strength, thermoplastic composite, Fiber content

\section{Introduction}

Fiber reinforced thermoplastics have been widely used in the manufacture of structural parts for aircraft and spacecraft due to their particular mechanical and physical properties such as high specific strength and high specific stiffness. Another relevant application for fiber-reinforced polymer composites (especially glass fiber-reinforced plastics) is in the electronics industry, where they are used to produce printed cable boards (Deogonda and Chalwa 2013).

Okereke and Michael (2016) examined the flexural reaction of E-glass fiber fortified polypropylene composite, tested the laminates by three-point bending with different crosses-ply and angle-ply arrangements. The results of the monotonic and cyclic flexural response showed that the laminates were affected by the plastic deformation of the matrix. Significant dissipation of energy, reduction of stiffness and piling of micro - damage specifically at the matrix - fiber interface observed when cyclic load numbers increased. (Abdullah et al. 2015) conducted a three - point bending tests for hybrid composites. Three types of fibers were selected together with an epoxy matrix (woven Kevlar, woven E-glass and random E-glass) to manufacture the composite laminates by hand lay-up process. Reinforcement arranged as: (three layers of woven glass), (three layers of woven Kevlar), (woven Kevlar-woven glass-woven Kevlar), (woven Kevlarrandom glass-woven Kevlar) and (woven glass-woven Kevlar-woven glass). The results of the bending test revealed that (Kevlar-regular glass-Kevlar) arrangement has the highest bending deflection $(8 \mathrm{~mm})$, whereas the lowest defect for (woven Kevlar-woven glass) arrangement (4.5 mm) was achieved.

The mechanical properties the glass fiber polymer composite mix with the natural fiber (sisal) has been presented by (Rana et al. 2017). Two layers of glass fiber blended with sisal fiber as a rate of $(0,2,4$, and $6 \%$ ) was reinforced with epoxy matrix composite. Approximately 4 percent increase in mechanical properties (tensile, flexural, impact) achieved and decrease after a certain proportion depending on the sisal fiber size and content. Flexure test results confirmed a clear improvement in the epoxy matrix of the sisal fiber reinforcement. The maximum flexural strength value achieved for composite with $10 \mathrm{~mm}$ sisal fiber length and maximum flexural modulus achieved for $15 \mathrm{~mm}$ length. Reinforcement composite materials have successfully substituted the traditional materials in several lightweight and high strength applications. 
The development of composite materials improves their performance based on the reinforcement of two or more fibers in a single polymeric matrix which leads to the advanced material system called hybrid composite with a great diversity of material properties. Thus, there is a need to investigate the mechanical properties like hardness, tensile strength, compression strength and flexural strength. The properties of a hybrid composite mainly depend upon the fiber content, length of individual fiber, orientation, extent of intermingling of fibers, fiber to matrix bonding and arrangement of both the fibers. The strength of the hybrid composite is also dependent on the failure strain of individual fibers. Maximum reinforcement results were obtained when the fibers are highly strain compatible. (Dong and Davies 2012, Satish et al. 2010)

The purpose of the present work is to development of fabrication technique and investigate flexural strength behavior of chopped glass fiber reinforcement thermoplastic (polyamide and polypropylene) subjected to variable percentage of reinforcement for accuracy in this work.

\section{Experimental work}

\subsection{Sample Preparation}

The two thermoplastics used in this study were polypropylene (PP) and polyamide (PA) reinforced by chopped glass fiber with different weight percentage $(10,20,30,40) \%$. The hot compression process used to fabricate the sheets for testing with different percentages of glass fiber. The polymers were granules mixed with chopped glass fiber and heated the mould up to $160{ }^{\circ} \mathrm{C}$ to melt the granules. At room temperature $(26 \pm$ 2) ${ }^{\circ} \mathrm{C}$, the sheets were left to solidify. For casting the sheet of composite material, the iron mould of dimensions (26, 14 and 1) cm length, width and thickness, respectively was used.

\subsection{Fiber volume fraction}

The constituent content of the composite materials test was conducted in accordance with ASTM D3171 11 (test method I) to determine the reinforcement weight content. This test method depends on the physical removal by ignition of the matrix (ASTM Standard D3171 2010). Composite specimen put in the furnace with known dimensions and weight and then heated up until the matrix is melted. The fiber was then isolated and cleaned with warm water, and the fiber is then weighted using a 4-digit digital balance (Fig. 1). A total of 8 tests have been conducted and repeated three times for each test and taking the average value.

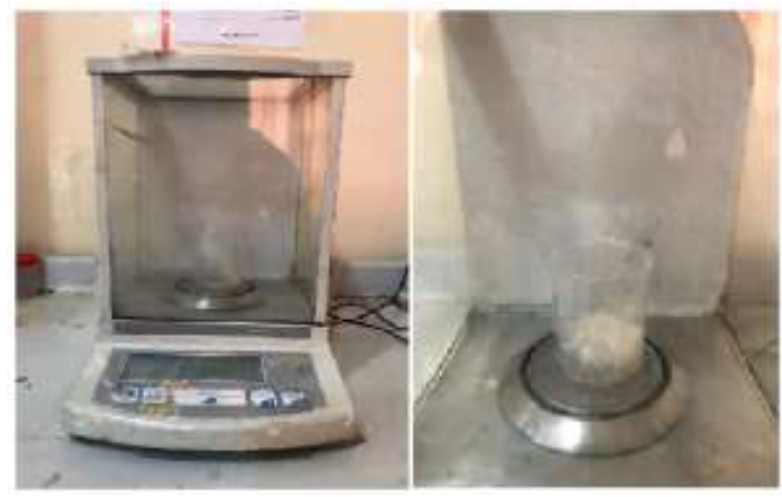

Figure 1. Digital balance.

\subsection{Three-point bending flexural test}

Three-point bending tests were conducted to study the flexural behavior of the composite specimens. An Instron universal testing machine (Fig. 2) with $5 \mathrm{kN}$ load capacity was used to perform these tests according to ASTM standard (D-790) (ASTM Standard D790 2003). The water jet cnc machine was used to cut rectangular specimens of dimensions (100x22mm), as shown in (Fig. 3). A total of 10 tests have been conducted and repeated three times for each test. 


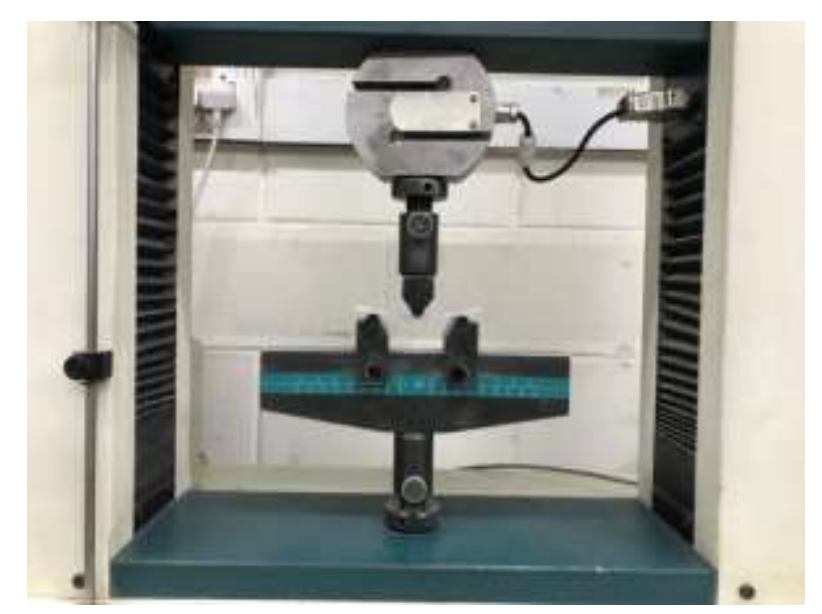

Figure 2. Flexural test.

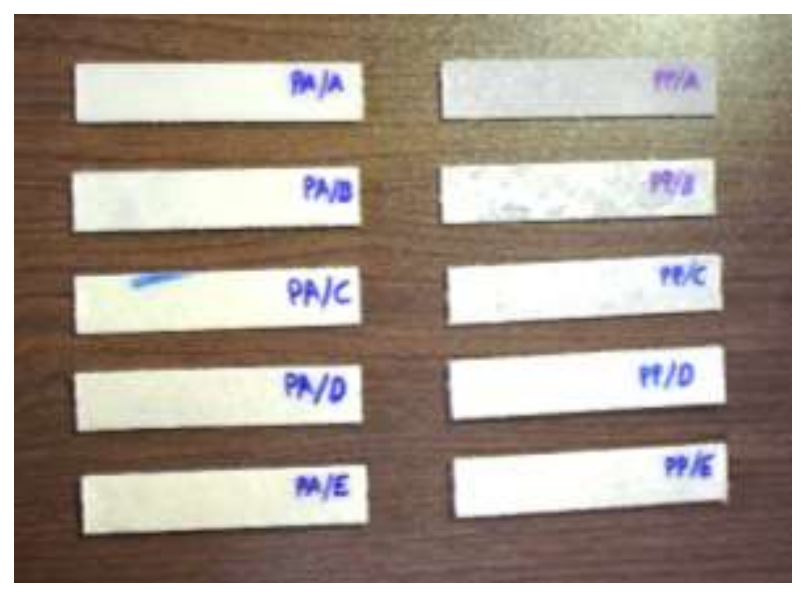

Figure 3. Specimens of flexural test.

\section{Result and discussion}

\subsection{Fiber content \% wt.}

The percentage of fiber content of composite materials evaluated as per the ASTM D3171. The results presented in the (Table 1). There is some disparity between the fiber content percentage values before and after the compression molding process. This disparity due to the leakage of some chopped fibers with the melted thermoplastic matrix during the compression molding process.

Table 1. Fiber content of thermoplastic composite sheets.

\begin{tabular}{|c|c|c|c|}
\hline \multirow[t]{2}{*}{ No. } & \multirow{2}{*}{$\begin{array}{l}\text { Fiber } \\
\text { content } \\
\text { before the } \\
\text { compression } \\
\text { molding (\% } \\
\text { wt.) }\end{array}$} & \multicolumn{2}{|c|}{$\begin{array}{l}\text { Fiber content } \\
\text { after the } \\
\text { compression } \\
\text { molding (\% wt.) }\end{array}$} \\
\hline & & GFRPA & GFRPP \\
\hline 1 & 0 & 0 & 0 \\
\hline 2 & 10 & 9.7 & 9.8 \\
\hline 3 & 20 & 19.4 & 19.7 \\
\hline 4 & 30 & 29.5 & 29.3 \\
\hline 5 & 40 & 39.2 & 39.6 \\
\hline
\end{tabular}


Flexural properties of the composite sheets at room temperature achieved according to the three-point bending test (ASTM D-790). The results show positive influence of fiber content ratio into the flexural strength of the composite sheets, as shown in (Fig. 4). Obviously, the enhancement in flexural strength is achieved by increasing the percentage of fiber content. If the matrices of polyamide and polypropylene reinforced by $40 \%$ of glass fibers, the maximum percentage of flexural strength enhancement is approximately $52 \%$ and $55 \%$ respectively.

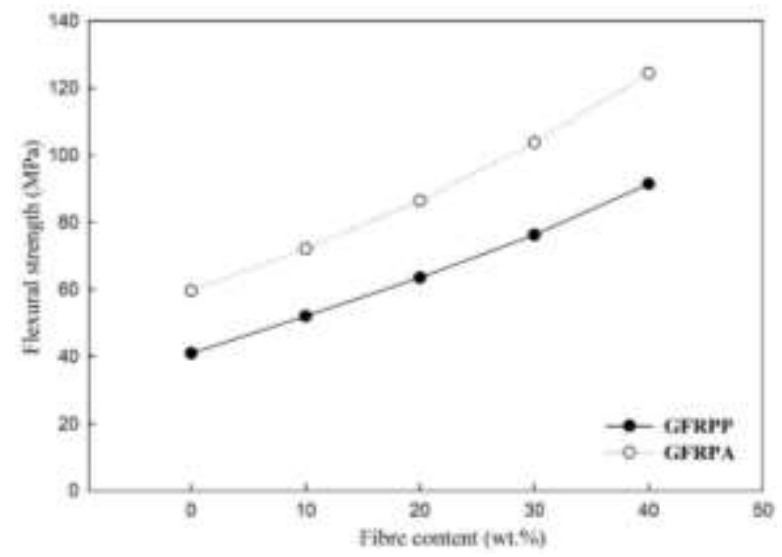

Figure 4. Effect of fiber content on the flexural strength.

Bending stresses are important in structure tests because of variety of loading situations in service. It determines the behavior and properties of the structure. Many parameters should be concerned test data. Polymeric composites are susceptible to mechanical damages when they are subjected to efforts of tension, flexural, compression which can lead to material failure. The mechanical properties of the materials are affected by many factors including: fiber type and volume fraction of the fiber. Figure.5 shows that stress strain curve from flexure test for pure polypropylene and polyamide that the relationship is linear with the increase of stress after yield point referred to in the figure, which is the boundary between the elastic deformation and the ductile deformation. Stress constantly from top to bottom expanding (craze) to lead to (crack) starting from the bottom surface of the sample and spread toward the upper surface of the sample, leading to the break. The reason is due to the fact that the polymeric chains consisting of the sample are intertwined, when you shed the stress on the sample will lead to the occurrence of landslides in the polymeric chains and move those chains in various directions until the occurrence of break-up (Ahmed 2011), while the composite samples show a different behavior according to the type of fiber although they were common to have a linear behavior initially and after noted displacement, where the curve began to fluctuate as shown in (Fig. 6).

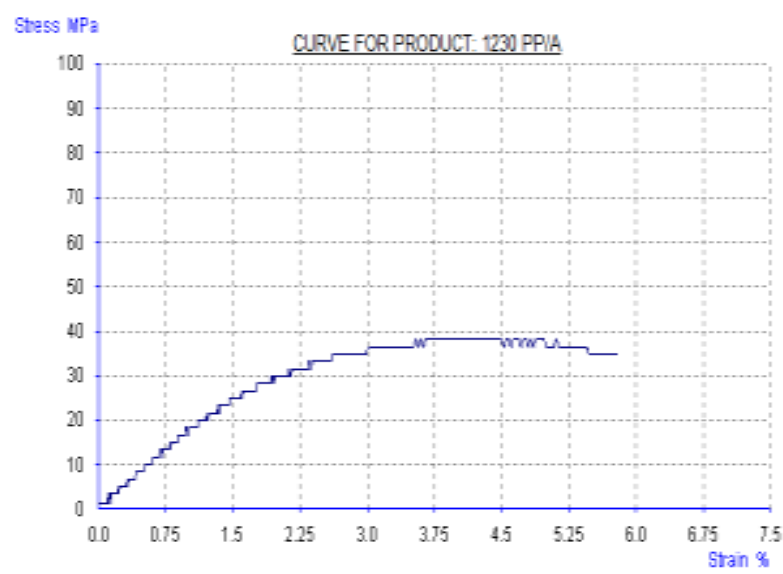

(a)

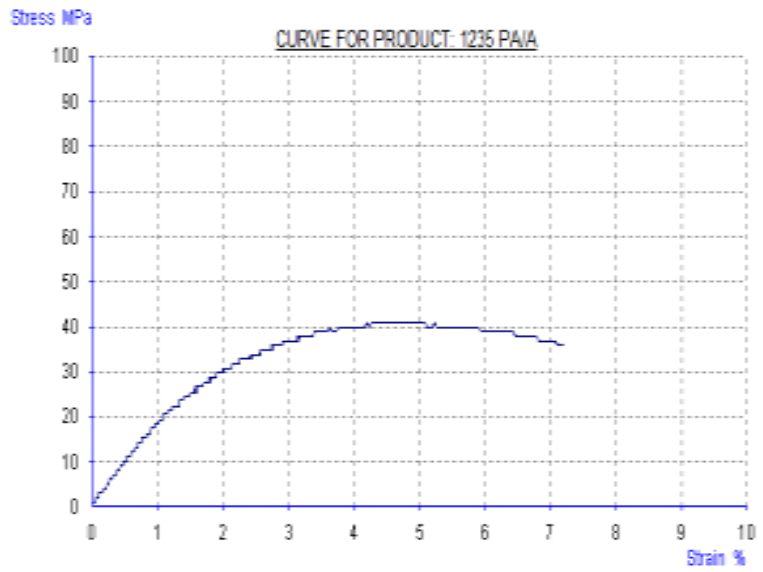

(b)

Figure 5. Stress-strain curve for polymers (a) Polypropylene (PP)

(b) Polyamide (PA). 
Figure 6 shows that the stress-strain curves for polymer reinforcement by different glass fiber percentage $(10,20,30,40) \%$ as symbol (B,C,D,E). It is known, (Table 2) show the mechanical properties of polymers can be improved by reinforcing them with fibers. During the flexural test, there are three factors dominate the resulting flexural strength of a specimen; the flexural strength of the matrix, the adhesion between fibers and matrix and the adhesion between laminates. This means that, the last two factors are added to the original strength of the matrix, and these two factors would lead to distribute the applied force on more cross-sectional area of the composite under test. (Fig. 6) there are two noticeable regions: the elastic region, and plastic region, it shows that the molecules slip passes each other normally to a small extent. After that point the craze show up which the material begin to deform numerous micro voids, the crack is initiated in the outer layer of the samples. The mechanism of failure is occurring when the critical state of stress in samples is reaching that will cause the appearance of critical value of crack and its unstable growth. The position of critical crack is associated with the fiber matrix deboning after which the fibers cracked. When the first break in the outer layer appeared it follows by more broken fibers (which was deboned and pulled out from the matrix). The crack propagates from the outer to the inner surface sample in transversal direction. The crack and delaminating appears in the samples as a result of shear stresses in the layers which is characteristic of bending test.

Table 2. Values of Yield Stresses, Young Modulus and Flexure strength for polymer composites.

\begin{tabular}{|c|c|c|c|c|c|}
\hline No. & Specimen & $\begin{array}{c}\text { Fiber } \\
\text { content } \\
\% \text { wt. }\end{array}$ & $\begin{array}{c}\text { Yield } \\
\text { point } \\
(\mathrm{MPa})\end{array}$ & $\begin{array}{c}\text { Young } \\
\text { Modulus } \\
(\mathrm{GPa})\end{array}$ & $\begin{array}{c}\text { Flexure } \\
\text { strength } \\
(\mathrm{MPa})\end{array}$ \\
\hline 1 & PP/A & 0 & 31.2 & 0.869 & 38.4 \\
\hline 2 & PP/B & 10 & 33 & 0.926 & 40.9 \\
\hline 3 & PP/C & 20 & 42 & 2.1 & 46.33 \\
\hline 4 & PP/D & 30 & 49.2 & 2.137 & 57.2 \\
\hline 5 & PP/E & 40 & 51.6 & 3.5 & 70.8 \\
\hline 6 & PA/A & 0 & 38.4 & 2.933 & 59.5 \\
\hline 7 & PA/B & 10 & 45 & 3.776 & 65.8 \\
\hline 8 & PA/C & 20 & 53 & 5.298 & 76.4 \\
\hline 9 & PA/D & 30 & 62.5 & 6.946 & 89.5 \\
\hline 10 & PA/E & 40 & 87 & 10.388 & 106.1 \\
\hline
\end{tabular}
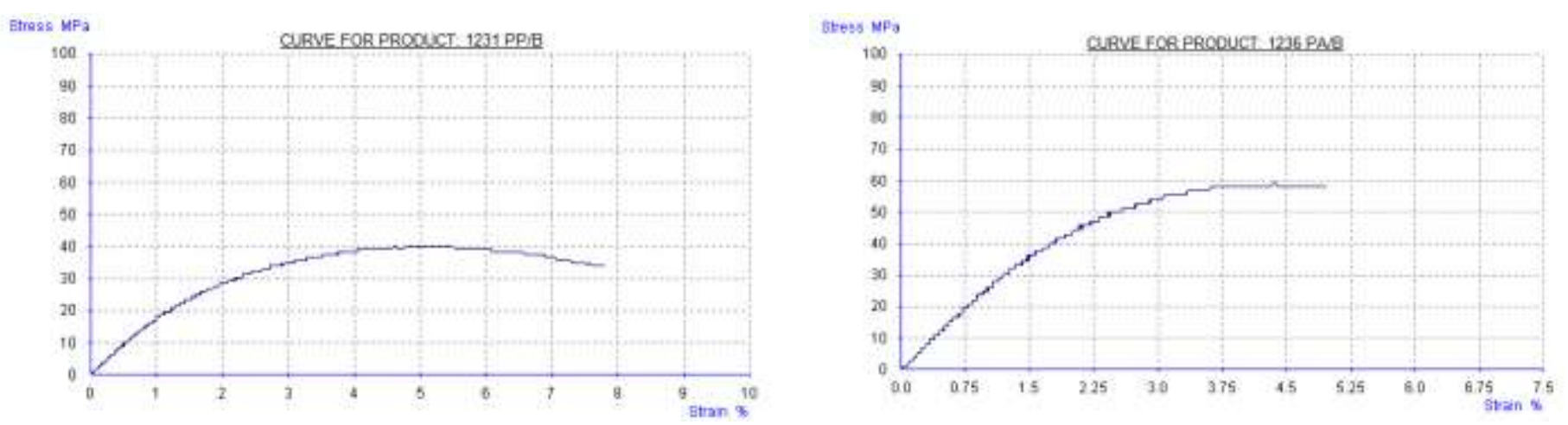

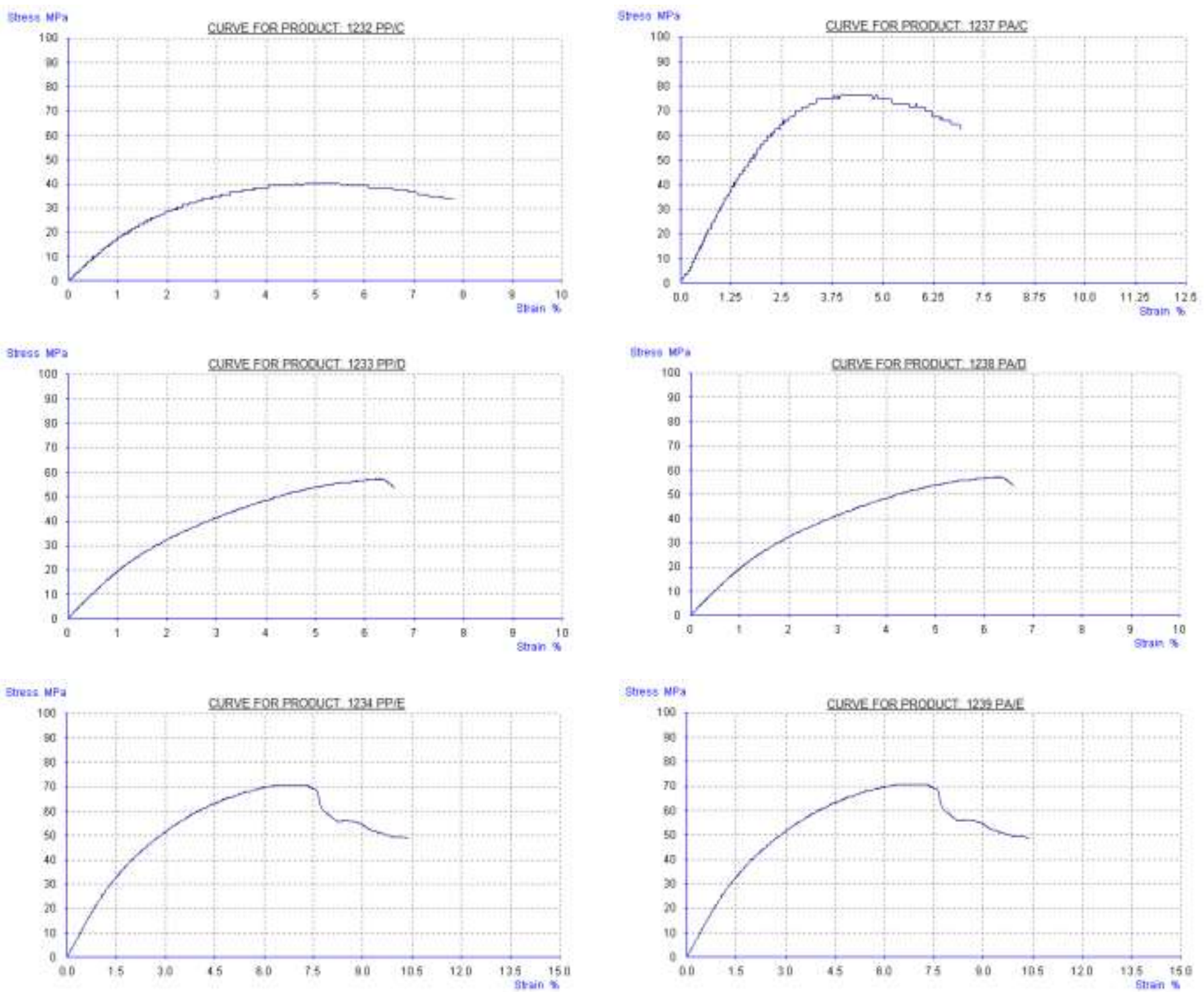

(a)

(b)

Figure 6. Stress -strain curve for polymer (PP, PA) reinforcement by different percentage of glass fiber.

\section{Conclusions}

One of the main conclusions drawn from the experimental investigations was the enhancement of the composite sheet bending strength with a fiberglass reinforcement percentage of (30 and $40 \% \mathrm{wt}$ ). Bending test results show that the samples which reinforced by (30 and 40) \%wt of fiber glass characterized the highest flexural strength which was 106.1 and $70.8 \mathrm{MPa}$ for glass fiber reinforcement polyamide (GFRPA) and glass fiber reinforced polypropylene (GFRPP), respectively. While the non-reinforced polymer has a lower flexural resistance than the sheets of composites strengthened by glass fiber. The lower flexural strength obtained for samples of sheets without reinforcement which was 59.5 and $38.4 \mathrm{MPa}$, for glass fiber reinforced polyamide (GFRPA) and glass fiber reinforced polypropylene (GFRPP), respectively. The flexural strength, Young's module and yield strength of glass fiber reinforced polyamide sheets were clearly greater than in glass fiber reinforced polypropylene sheets.

\section{References}

[1] Patil Deogonda, Vijaykumar N Chalwa (2013) Mechanical Property of Glass Fiber Reinforcement Epoxy Composite: International Journal of Scientific Engineering and Research (IJSER) Volume1 Issue 4, December.

[2] Okereke, Michael I. (2016): Flexural response of polypropylene/E-glass fibre reinforced unidirectional composites, Composites Part B: Engineering 89: 388-396. 
[3] Abdullah, Hind W., Harath I. Jaffa, and Khalid R. Al-Rawi. (2015): Study of Bending Property for Epoxy/Kevlar-Glass Fibers and Hybrid Composite. Engineering and Technology Journal33, No. 9 Part (B) Scientific: 1635-1642.

[4] Rana, R. and R. Purohit (2017). A Review on mechanical property of sisal glass fiber reinforced polymer composites. Materials Today: Proceedings 4(2): 3466-3476.

[5] Chensong Dong and Ian J. Davies (2012): Optimal Design for the flexural behavior of glass and carbon fiber reinforced polymer hybrid composites, Materials Design, Vol.37.

[6] K.G. Satish, B. Siddeswarappa and K. Mohamed Kaleemulla (2010): Characterization of In-plane mechanical properties of laminated hybrid composites, Journal of Miner Mat Char Eng, Vol.9 (2).

[7] ASTM Standard D3171 (2010): Standard Test Methods for Constituent Content of Composite Materials. West Conshohocken (PA): ASTM International.

[8] ASTM Standard D 790 (2003): Standard Test Methods for Flexural Properties of Unreinforced and Reinforced Plastics and Electrical Insulating Materials. West Conshohocken (PA): ASTM International.

[9] Ahmed Jdah, F. (2011): Investigation of Some Mechanical Properties of Sawdust and Chopped Reeds/UPE Composites, M.Sc. Thesis. Department of physics. University of Baghdad. 